\title{
Characterization and analysis of metropolitan freight patterns in Medellin, Colombia
}

\author{
Carlos A. Gonzalez-Calderon ${ }^{1 *} \mathbb{B}$, Iván Sánchez-Díaz ${ }^{2}$, Iván Sarmiento-Ordosgoitia ${ }^{3}$ and José Holguín-Veras ${ }^{4}$
}

\begin{abstract}
Purpose: This paper seeks to pilot test a novel way to collect freight and service activity data and analyze the collected data in the metropolitan area of Medellin, Colombia.

Methods: This research collects data using a multi-layer and multi-actor approach that includes surveys to receivers, suppliers, carriers, and truck drivers. The data are used by the authors to describe the overall freight patterns in the area of study and to show lessons learned.

Results: The data collection resulted in 2947 establishments (4.4\% of the total establishments in the city), a cordon survey of 2950 commercial vehicles (17\% of the total vehicle volume) accessing the urban area, and carrier interviews to ten companies and 130 truck drivers. The results indicate that a total of 33,274 metric tons/day enter the study area, 35,240 tons/day leave the area; while 7000 tons/day are distributed in the study area. In terms of freight trips, 6600 trips/day enter the study zone and 6600 trips/day leave it.

Conclusions: The data collection effort enabled the analyses of freight generation patterns. The freight surveys used in the study complement each other, and provided a good depiction of the freight movements in urban areas. It was found that in the Medellin Metropolitan Area, freight-intensive sector establishments generates, on average, significantly more cargo (freight attraction plus production) than the service-intensive sectors. The analyses of the surveys allow the decision makers to understand the nature of the cargo and the generation patterns in different type of establishments. This characterization of the freight patterns is vital for the forecasting of the behavior of the cargo and it is the main input to perform freight demand modeling for city planning, especially for developing countries, where there are too many budget constraints.
\end{abstract}

Keywords: Urban freight, Cordon survey, Establishments' survey, Urban freight patterns

\section{Introduction}

The movement of goods is an essential factor in the economy of cities, regions, and countries. In recent years the quest for sustainability has motivated policy makers to find strategies that reduce the externalities produced (e.g., congestion, pollution, noise) while protecting and enhancing its economic benefits. ${ }^{1}$ It is crucial to understand the patterns of goods movements to be able to formulate alternatives that advance sustainability and economic progress.

\footnotetext{
* Correspondence: cagonza0@unal.edu.co

'Department of Civil Engineering, Universidad Nacional de Colombia at Medellin, Calle 65 \# 78-28, M1-110 Medellin, Colombia

Full list of author information is available at the end of the article
}

Freight activity is difficult to understand because there are many actors involved (e.g., shippers, carriers, distributors, freight forwarders, receivers) involved in multiple industry segments and not much information is available about how they operate. As a result, characterizing freight patterns require a multi-layer and multi-actor approach. Goods movements can be broadly divided in three clusters: (1) the flows of commodities resulting from economic transactions that arrive through international gateways (e.g., ports, airports) and are then transported to manufacturing districts or to wholesalers for distribution; (2) the flows of commodities that are consumed by manufacturers, transformed, and then shipped again to local or international destinations; and 
(3) the flows of commodities that are distributed for final consumption (e.g., supplies for retail stores). These three types of flows converge in urban environments. While most of the attention has traditionally focused on the first and the second clusters because they move the largest amounts of cargo, the bulk of freight trips-and their negative impacts-are produced by urban deliveries, that are actually the focus of the "City Logistics" initiatives.

Complicating things there is a lack of data about freight demand, especially in developing countries. The lack of data is the result of multiple factors: the difficulty of collecting the data, lack of awareness about the importance of proactive public-sector involvement in freight transportation management, the cost of collecting the data, among other reasons.

The recent data collection in Medellin (the data were collected in 2011-2012 by the Universidad Nacional de Colombia at Medellin - that is the focus of this paper-is an interesting case because it is a comprehensive effort to characterize a city's freight activity patterns.

The freight study reported in this paper is unique because it pilot test the freight data collection approach outlined by [1]. This innovative approach pieces together different surveys to carriers, receivers, manufacturers, and others; and combines data collection and modeling to obtain fine-level detail of freight activity. Additional details are presented in section 5 .

To the best of the authors' knowledge, this is the first freight survey done in the Metropolitan Area of Medellin; for that reason, the results obtained are essential to support freight policy making in the Medellin Metropolitan Area. The lessons learned in this effort are relevant to countries all over the world where there are limited resources for freight data collection.

This paper has five additional sections to this introduction. Section 2 gives a background summary of freight studies. Section 3 presents the description of the case study characterizing the cargo in Medellin. Section 4 shows the data collection conducted. Section 5 analyses the results emphasizing on freight generation patterns. Finally, Section 6 summarizes the main findings and conclusions.

\section{Background summary on freight studies}

To understand the system as a whole, relevant data need to be collected. Usually this information is obtained through surveys that are carried out at different places. The movement of cargo in a region can be captured basically from three types of freight surveys that complement each other (1) establishment surveys that target the producers and consumers of goods to estimate freight production and attraction inside the urban area; (2) distributor surveys that capture information on goods movements through intermediaries but sometimes are difficult to conduct because of the confidentiality of the data; and (3) carrier surveys that quantify freight patterns in terms of commercial vehicle flows in the transportation network [2]. Considering the information that can be captured from different type of surveys, professionals in charge of estimating freight demand in urban regions must identify the commercial characteristics of the city in order to select the best type of freight surveys to be conducted. It is important to note that typically one survey type cannot capture all the freight information in a region. For example, origin-destination surveys-which are the most common method to obtain information of truck travel patterns in a city-do not allow to draw a complete picture of all the freight patterns in a city because they miss freight data (e.g., traffic counts, freight generation) to represent the freight traffic flows on the transportation network.

Allen, et al. [3] presented a complete revision of 162 studies of urban freight that collected urban freight data from the 1960's to 2008 in 18 countries. Only 28 studies were made in the period 1960-1989. The rest (134) were made from 1990 to 2008 showing an increment of the practice in recent years, especially in Europe. This increase in the number of freight studies could be due to new techniques in collecting data and interest of the public sector in the freight movements. However, it is important to note that many freight data collection efforts are not published in journals or in English. Most of them are reports written in the language of the region/country that sometimes are not disseminated or simply archived.

This paper describes the process followed and presents the results obtained from a multilayer data collection approaches based on Holguín-Veras and Jaller [1]. This approach includes a cordon survey, an establishment-based survey, and a carrier survey. This gathering of freight data is essential to city planning due to the economic implications of it. The study presented here provides an example of how the freight information collected in Medellin was used to obtain freight patterns of this developing city, and eventually the process could be applied in similar urban areas. ${ }^{2}$

\section{Area description}

The Medellin Metropolitan Area (MMA) includes the city of Medellin (the second largest city in Colombia) and nine other urban areas, with approximately 3.5 million inhabitants and 67,800 commercial establishments (19.4 establishments for every 1000 inhabitants) in 2012 [4]. Medellin is an important industrial city in Colombia due to its manufacturing activity and its contribution to GDP, the largest one after Bogota, the capital [4]. The MMA has an international airport to plays an important role in the import and export of goods, especially flowers. 
The Northern counties represent $15 \%$ of the population but account for less than $4 \%$ of the establishments in the study area; a likely consequence of the low income nature of this part of the metropolitan area. Conversely, the Southern counties, with a similar share of population, concentrate $10 \%$ of the establishments. This reflects their relatively high income and the presence of manufacturing in this part of the MMA. The urban core, Medellin, gathers $70 \%$ of the population and about $85 \%$ of the establishments. Needless to say, the urban core plays a major role in terms of commercial activity, suffering the largest freight-related traffic impacts, even in the main road corridor that traverses the city.

The zoning system used in the study consists of 456 transportation analysis zones (TAZs). Those TAZs are based on previously studied areas/regions of the city [4] that facilitate the analyses of the results and comparison with previous transportation studies. The geographical distribution of the establishments in the city of Medellin-where the freight surveys took place-is shown in Fig. 1. The blue color indicates less presence of establishments while the red color indicates the opposite.

The circles in the figure show the Central Business District (CBD) and El Poblado-a dense commercial area in the south of Medellin where the highest income population live, which is emerging as a secondary business district-. The CBD and El Poblado concentrate more than $60 \%$ of the commercial establishments in the metropolitan area, which generate large freight and trips movements in the area. The areas with no establishments (blank spaces) in the map correspond to hills, rivers, and the like.

\section{Data collection}

This section describes the methodology conducted to obtain the freight data in the study area. The first subsection explains different freight surveys. The second subsection summarizes the freight surveys conducted in the study.

\subsection{Brief description of overall approach / methodology}

This paper is based on the work done by Holguín-Veras, et al. [5]. The authors identified the main freight demand modeling techniques, determined their main data requirements, proposed a data collection methodology combining multiple methods, measuring different units and targeting multiple agents to obtain a comprehensive view of freight activity. In doing so, the authors proposed a data collection framework that includes establishment-based surveys (receiver, shipper, and carrier), trip intercept-based surveys, cordon surveys, vehicle-based surveys, and tour-based surveys. They suggested that the data collected should meet the expectation of the planning agency that is going to use them, should be cost-efficient, should be oriented to fill data gaps, and become the basis for freight demand synthesis. In other words: "the best approach will be the combination of data collection procedures (that best fits the needs and constraints of the participating agencies)" [5].

The main intent of the freight data collection effort was to characterize the freight activity that takes place in all stages of the supply chains in the MMA. Some of the key data to be collected includes: 1) origin and destination of the trip; 2) commodities being transported

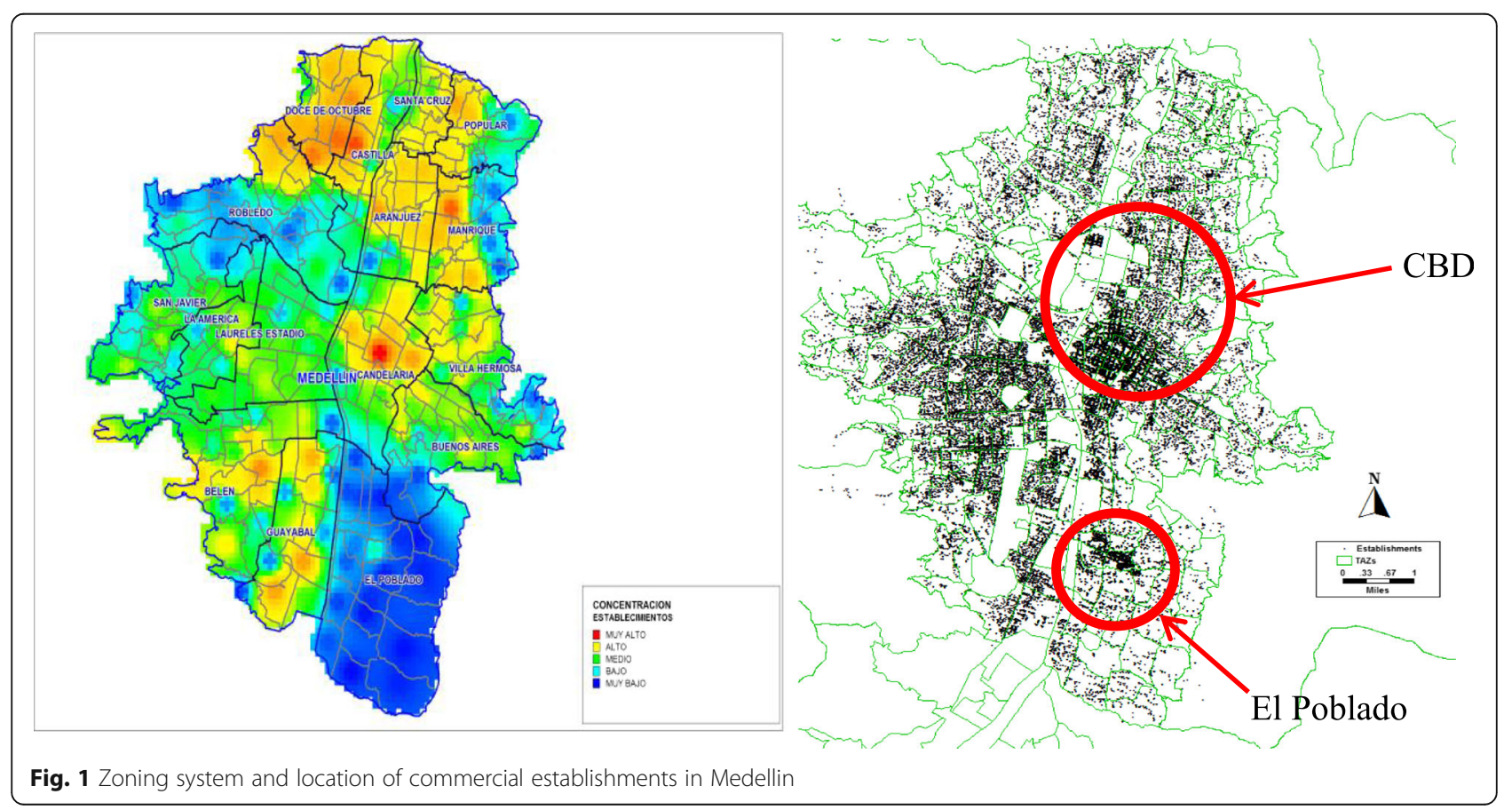


(quantity, unit, weight, and industrial sector); 3) commercial vehicle being used (vehicle type, vehicle configuration, number of axels, number of stops per tour, capacity, percentage of cargo transported, and load factor); 4) vehicle delivery/collection trips at establishments; 5) goods flows to/from establishments; 6) loading/ unloading activity of goods vehicles; 7) parking activity of trucks; 8) trip details and patterns of goods vehicles; 7) conveyance of goods between vehicles and establishments; 10) origin location of goods flow/vehicle trip to establishment; 11) supply chain management between establishments, their suppliers and freight transport operators; and 12) Goods order (food/pharmacy) from stores nearby.

Some of the key mechanisms to collect freight data include:

- Cordon survey: During the week days, it is common that about $50 \%$ of the traffic entering the city is comprised of large trucks, thus the importance of measuring the entering flows though cordon surveys [4]. The questionnaire should contain questions about origin and destination of the trip, commodities being transported (quantity, unit, weight, and industrial sector) and the commercial vehicle being used (vehicle type, vehicle configuration, number of axels, number of stops per tour, capacity, percentage of cargo transported, and load factor).

- Establishment survey: The establishments need to be geo-located and classified in industry sectors using an appropriate classification system differentiating between freight-intensive sectors (e.g., mineral; construction; manufacturing; accommodation and food, transportation; wholesale trade; retail trade; food) and service-intensive sectors (e.g., finance, insurance and real estate; service industries; public administration). The data need to be collected through surveys. A set of expansion factors, relating the sample to the universe for each industry code, needs to be applied to the survey results to obtain the overall picture of internal freight activity. The questionnaire should contain questions about vehicle delivery/collection trips at establishments; goods flows to/from establishments; loading/unloading activity of goods vehicles; and parking activity of service vehicles.

- Carrier interviews: to complement the establishment and cordon surveys, a carrier survey should be conducted to companies and truck drivers at the urban area to validate some practices of behavioral aspects of the urban deliveries and logistics practices for different industry sectors. The questionnaire should contain questions about trip details and patterns of goods and service vehicles; conveyance of goods between vehicles and establishments; and supply chain management between establishments, their suppliers and freight transport operators. The survey should be done with the help of the private sector officials of the city to facilitate the process.

\subsection{Data collection}

The data collection procedure used by the authors was based on the following components:

- Cordon survey: The survey was conducted between October and November of 2011 to 2950 commercial vehicles (17\% of the incoming flow) in 11 tollbooths in the boundaries of Medellin to capture the flows entering and exiting the city. The surveys were conducted, for security and practical purposes from 6 AM to 7 PM and with the help of the highway police.

- Establishment survey: The establishments were geolocated and classified in 20 industry sectors using the International Industrial Uniform Code (IIUC) [4]. Thirteen sectors were classified as freightintensive sectors (e.g., mineral; construction; manufacturing; accommodation and food, transportation; wholesale trade; retail trade; food) while the other seven are service-oriented (e.g., finance, insurance and real estate; service industries; public administration). The geo-location of the establishments in the study area made possible the design of a sample that respects the geographical breakdown of establishments with about $13 \%$ at north, $13 \%$ at south, and $74 \%$ in Medellin. The sample was randomly drawn across the ten municipalities of the region. Only $1 \%$ of the establishments listed were not considered in the sample because they are located in rural areas not covered by the survey. Similarly to the geographical distribution, the sample was designed to reproduce the distribution of industry segments with the exception of the large establishments (more than 200 employees), due to lack of data for this type of establishements. Most of the IIUCs were considered in the sample. The only exceptions were agriculture, livestock, fishing (usually not present in urban areas), other housing service activities, and other services. The data were collected through surveys in 4 months (between February and May of 2012) with a sample of 2947 establishments (4.4\% of the total). About $2 \%$ had major errors and were excluded from the expansion procedure. A set of expansion factors, relating the sample to the universe for each IIUC, were applied to the survey results to obtain the overall picture of internal freight activity.

- Carrier interviews: to complement the establishment and cordon surveys, a carrier survey was applied to ten companies and 130 truck drivers at the urban area to validate some practices of behavioral aspects 
of the urban deliveries and logistics practices for different industry sectors. The survey was done with the help of the police, which collaborated in this process in 2012.

Table 1 summarizes the freight data used for the study. Once the data were collected and cleaned, the authors proceeded with their descriptive analysis that is presented in the next section.

\section{Results}

This section presents the descriptive analyses of the data. The first part of the section describes the results for the cordon surveys, while the second presents the results for the establishments, and carriers, surveys. The results should be analyzed as a global finding because each freight survey complements the rest.

\subsection{Cordon surveys}

The results from the cordon survey provide a panoramic view of freight flows of the MMA. The results show that 33,274 tons enter the metropolitan area every day; 35,240 tons leave it, and additionally, 27,653 are external to external flows. An additional 2400 tons of trash as well as 8000 tons of construction materials waste (debris) are produced and transported every day within the metropolitan area. $^{3}$ The external-internal and internal-external flows are similar (30\% of the total each) and $85 \%$ of the cargo is transported by trucks. Inside the region, $15 \%$ of the cargo is composed by the flows between small establishments, debris, and trash.

The results of the cordon survey show that considering all the cargo in the city, the amount of freight moved

Table 1 Freight data used for the study

\begin{tabular}{|c|c|c|}
\hline Data collection & Observations & Variables \\
\hline \multirow{3}{*}{$\begin{array}{l}\text { Cordon } \\
\text { survey }\end{array}$} & \multirow{3}{*}{$\begin{array}{l}2950 \text { commercial } \\
\text { vehicles }\end{array}$} & Origin and destination of the trip \\
\hline & & Commodities being transported \\
\hline & & Commercial vehicle being used \\
\hline \multirow[t]{4}{*}{$\begin{array}{l}\text { Establishment } \\
\text { survey }\end{array}$} & \multirow[t]{4}{*}{2947 establishments } & $\begin{array}{l}\text { Vehicle delivery/collection } \\
\text { trips at establishments }\end{array}$ \\
\hline & & $\begin{array}{l}\text { Goods flows to/from } \\
\text { establishments }\end{array}$ \\
\hline & & $\begin{array}{l}\text { Loading/unloading activity of } \\
\text { goods vehicles }\end{array}$ \\
\hline & & Parking activity of trucks \\
\hline \multirow[t]{3}{*}{$\begin{array}{l}\text { Carrier } \\
\text { interview }\end{array}$} & \multirow{3}{*}{$\begin{array}{l}10 \text { companies } \\
\text { and } 130 \text { truck } \\
\text { drivers }\end{array}$} & $\begin{array}{l}\text { Trip details and patterns of } \\
\text { goods vehicles }\end{array}$ \\
\hline & & $\begin{array}{l}\text { Conveyance of goods between } \\
\text { vehicles and establishments }\end{array}$ \\
\hline & & $\begin{array}{l}\text { Supply chain management } \\
\text { between establishments, their } \\
\text { suppliers and freight transport } \\
\text { operators }\end{array}$ \\
\hline
\end{tabular}

per person in the Medellin Metropolitan Area is about $25 \mathrm{~kg} /$ day (total cargo divided by population), without taking into account the freight passing through the region. This value is an interesting indicator related to the intensity of freight activity and consumption patterns in the region. ${ }^{4}$ The amount of cargo consumed by person in a city is related to the proportion of freight activity (population and number establishments) in the regions and to the purchasing power of people. ${ }^{5}$

Table 2 shows the commodities transported by vehicle type. As shown, in terms of daily trips, 17,550 commercial vehicles enter, leave, or pass through the metropolitan area, and $22 \%$ of the total trips are empty. This proportion of empty trips is a typical pattern in Colombia and other countries [6-9]. Moreover, in terms of freight trips, the results show that only $10 \%$ of daily trips are external trips, the remaining $90 \%$ are internal. It is noteworthy that $21 \%$ of the cargo is transported in large trucks with large shipment sizes. This reflects the fact that the majority of the cargo inside the city is being transported in small trucks, autos, and motorcycles (79\%). That produce $90 \%$ of the daily freight trips without doubt the large traffic or small trucks create negative externalities such as congestion, emissions, and noise. The commodities transported that have the largest market share in the MMA are: Manufacturing (22\%), Food (21\%); Parcels (13\%), Construction (11\%), Chemicals (8\%), and Animals (3\%). The results also indicate that approximately $4 \%$ of the vehicles entering the region were light vehicles (autos, pick-ups, and motorcycles), $11 \%$ small trucks and $71 \%$ medium trucks and $14 \%$ large trucks. These shares of vehicle types are different from the ones in the city where small vehicles are the most common. The vast majority of the vehicles in the cordon survey are medium-large trucks (85\%) which transport large amounts of cargo in and out the city.

In terms of trip chains, the surveys inquired about the number of stops per tour by commodity type. As shown in Holguín-Veras [10], the number of tours depends on the characteristics of the country, city, type of truck, the number of trip chains, type of carrier, service time, and commodity transported.

In terms of commodity type, the authors found that the average number of stops vary between 1 (e.g., magazines, coffee, leather) and 10 (e.g., lubricants, beverages, aluminum) with an average of 2.6 stops per tour as shown in Fig. 2. Moreover, in general $66 \%$ of the trucks make 1 stop (only one destination), 31\% make between 2 and 10 stops, and 3\% make more than 10 stops. As expected, the frequency reduces as the number of stops increases.

\subsection{Establishment and carrier surveys}

The results from the establishment survey provides a panoramic view of freight production and attraction in 
Table 2 Commodities transported by vehicle type

\begin{tabular}{|c|c|c|c|c|c|c|c|c|}
\hline Vehicle/commodity & Food & Animals & Construction & Parcels & Manufacturing & Chemical & Empty & Total \\
\hline Small vehicles & 2943 & 427 & 1416 & 2010 & 3338 & 677 & 3140 & 13,950 \\
\hline Large vehicles & 749 & 60 & 523 & 238 & 504 & 751 & 776 & 3601 \\
\hline Total & 3693 & 487 & 1939 & 2248 & 3841 & 1428 & 3917 & 17,551 \\
\hline
\end{tabular}

the metropolitan area of Medellin. Although the cordon survey showed that about 33,000 tons enter and leave the area of study every day, the establishment survey shows that about 7000 tons are transported between small and medium size establishments; and 1000 tons have a destination outside the region, then the freight movement inside the metropolitan area reaches 6000 ton/day. In terms of trips, the bulk is generated by urban deliveries. Small establishments produce and attract 94,000 trips which is about 6 times the near 17,000 truck trips captured in the external cordon survey. In contrast, the tonnage entering and leaving the region is near 12 times the tonnage produced and attracted inside the MMA. Considering the number of trips and cargo, we noticed that large establishments (establishments with more than 200 employees) is not the main source of the freight traffic, but the large number of trips of small vehicles are produced inside this area to distribute the cargo.

The analysis shows that $71 \%$ of the establishments do not have storage space. This creates the imperative need for frequent deliveries. It was also found that $45 \%$ of the establishments open between 7:00 and 8:00 a.m., and 40\% of the establishments close between 5:00 and 6:00 p.m. $87 \%$ of the cargo by tonnage is moved by trucks, pick-ups and autos, the remaining $13 \%$ if transported by motorcycle. Data show that $70 \%$ of the trucks park in the street for loading/unloading (in 20\% of the cases they reported to park illegally though the real number could be higher). Of great interest to this paper, the average time for loading/unloading vehicles is $18.5 \mathrm{~min}$. This is a general average for all sectors because the loading/unloading activity was variable even in the same industry sector. These long parking times, combined with the lack of appropriate loading/unloading facilities, have negative effects in terms of street blockages and the resulting congestion.

Table 3 shows the breakdown of trips and tonnage by industry sector. After applying the expansion factors to the samples, the total number of trips and tonnage were computed by industry sector.

A breakdown by industry sector reveals that most of the observations are in the wholesale trade sector (34\%), retail (28\%), and accommodation and food (16\%). In terms of business size, most of the establishments in the sample are small to medium-sized, i.e., less than 50 employees (90\%). Furthermore, $90 \%$ of the establishments in Medellin have less than 10 employees, and $8 \%$ have between 11 and 50 employees. All these establishments are micro and small business with an average of 3.2 employees.

The results indicate that the large freight generators (e.g., large buildings, universities, hospitals) concentrate $26 \%$ of the cargo with only $4.6 \%$ of the trips in the city. The manufacturing, retail, and services sectors concentrate about $80 \%$ of the deliveries and $53 \%$ of tonnage. Every delivery of these three sectors weights on average less than $50 \mathrm{~kg}$. If the large generators are included the number of deliveries reaches about $85 \%$ and the tonnage around $80 \%$. In terms of the delivery size, the average looks small with $64 \mathrm{~kg}$ per delivery. It could be due to the high presence of the retail sector in the city logistics. However, large generators receive the heaviest deliveries with $361 \mathrm{~kg}$, and other sectors like wholesale trade receive $110 \mathrm{~kg}$ per delivery on average.

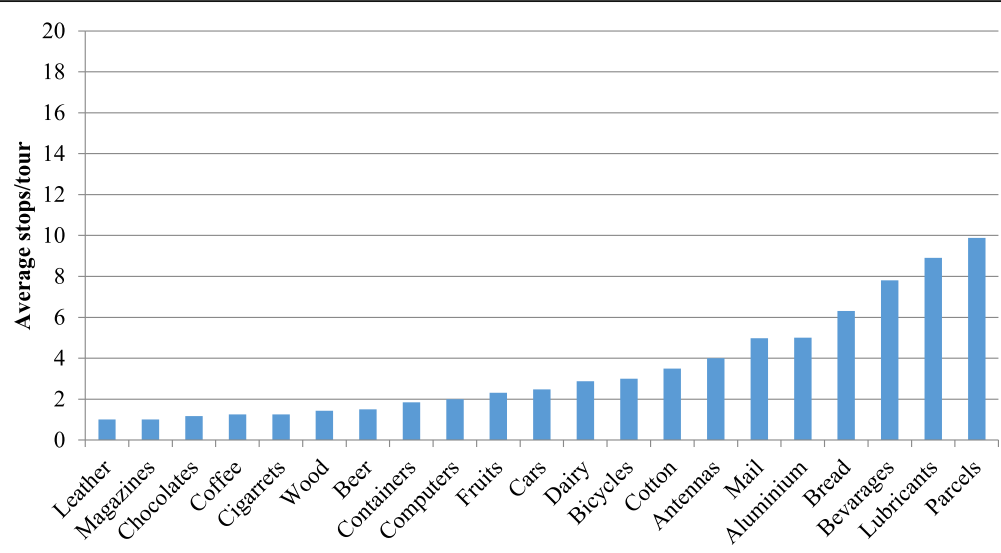

Fig. 2 Average number of stops per commodity type 
Table 3 Breakdown of trips and tonnage by industry classification

\begin{tabular}{|c|c|c|c|c|c|}
\hline Industry classification & Trips/day & $\%$ of trips & Tons/day & $\%$ of tonnage & $\mathrm{Kg} /$ trip \\
\hline Retail trade & 28,018 & $29.7 \%$ & 1200 & $19.8 \%$ & 42.8 \\
\hline Manufacturing & 24,812 & $26.3 \%$ & 1317 & $21.7 \%$ & 53.1 \\
\hline Wholesale trade & 6920 & $7.3 \%$ & 763 & $12.6 \%$ & 110.3 \\
\hline Construction & 4170 & $4.4 \%$ & 300 & $5.0 \%$ & 71.9 \\
\hline For hire carriage & 2361 & $2.5 \%$ & 59 & $1.0 \%$ & 25.0 \\
\hline Services & 21,665 & $23.0 \%$ & 695 & $11.5 \%$ & 32.1 \\
\hline Utilities/communication & 183 & $0.2 \%$ & 7 & $0.1 \%$ & 38.3 \\
\hline Public administration & 12 & $0.0 \%$ & 3 & $0.0 \%$ & 250.0 \\
\hline Large freight generators & 4364 & $4.6 \%$ & 1577 & $26.0 \%$ & 361.4 \\
\hline Agriculture & 0 & $0.0 \%$ & 0 & $0.0 \%$ & 0.0 \\
\hline Mining & 1528 & $1.6 \%$ & 109 & $1.8 \%$ & 71.3 \\
\hline Unclassified & 151 & $0.2 \%$ & 30 & $0.5 \%$ & 198.7 \\
\hline Total & 94,184 & $100.0 \%$ & 6060 & $100.0 \%$ & 64.3 \\
\hline
\end{tabular}

Another interesting finding from the study was the vehicle classes used to transport the freight within the metropolitan area. Table 4 shows the daily breakdown of trips and tonnage by vehicle class for the sample.

As shown in Table 4, more than two thirds of freight inside the metropolitan area are transported in trucks. Another 33\% of freight is transported in smaller vehicles: $11 \%$ transported by pickups and vans, about $9 \%$ by cars and about $14 \%$ by motorcycles and bicycles. As shown, bicycles and motorcycles produce a large amount of trips (14\%) and transport a small amount of tonnage $(5.5 \%)$. Tables 5,6 , and 7 present the descriptive statistics of the different economic sectors for selected business attributes of Freight Intensive Sectors (FIS)-industry sectors that generate more freight-, Service Intensive Sectors (SIS) - industry sectors that generate less freight and more services-, and all commercial establishments, respectively.

As shown in Tables 5, 6 and 7, the economic sectors can be broadly classified as FIS (freight-related) and SIS (service oriented). The former includes establishments where the main economic activity depends on cargo handling (e.g., manufacturing, wholesale, and retail establishments), while for the latter the main source of revenue are service activities (e.g., public services, financial services). The overall average for employees per establishment is 9.1 employees. The average employment for FIS establishments is 8.8, while the average for non-FIS ones is 10.2. The transport/warehousing sector has the highest average of employees per establishment (39.7), followed by service-oriented sectors education (17.13), health and social services (17.13), and financial services (17.01).

In terms of area, the overall average is $157 \mathrm{~m}^{2}$; FIS establishments are, on average, $162.4 \mathrm{~m}^{2}$; while servicerelated establishments are $158.2 \mathrm{~m}^{2}$. The largest area per establishment is found in the education industry (288. $4 \mathrm{~m}^{2}$ ), followed by medium manufacturing $\left(258.5 \mathrm{~m}^{2}\right)$ and transportation and warehousing $\left(211.8 \mathrm{~m}^{2}\right)$; while, the smallest area per establishment is found for mining $\left(87.3 \mathrm{~m}^{2}\right)$, fuel/lubricants distribution $\left(85.9 \mathrm{~m}^{2}\right)$, machine renting $\left(83.9 \mathrm{~m}^{2}\right)$, and utilities $\left(53.3 \mathrm{~m}^{2}\right)$. Although there is a large variance of business size within a single sector, these numbers shed light on the type of establishments included in those sectors.

As expected, FIS establishments generate, on average, more freight (freight attraction plus production) than

Table 4 Breakdown of trips and tonnage by vehicle class

\begin{tabular}{llllll}
\hline Transportation mode & Daily trips & Daily Kilograms & Average Kgs/trip & Percent of trips & Percent of tones \\
\hline All trucks & 3882 & 267,546 & 68.9 & $64.4 \%$ & $72.7 \%$ \\
Pick-ups and vans & 692 & 41,540 & 60.1 & $11.5 \%$ & $11.3 \%$ \\
Cars & 491 & 35,490 & 72.2 & $8.1 \%$ & $9.6 \%$ \\
Motorcycles & 626 & 17,162 & 27.4 & $10.4 \%$ & $4.7 \%$ \\
Bicycles & 201 & 2811 & 14.0 & $3.3 \%$ & $0.8 \%$ \\
Others & 138 & 3346 & 24.2 & $2.3 \%$ & $0.9 \%$ \\
Total & 6031 & 367,896 & 44.5 & $100.0 \%$ & $100.0 \%$ \\
\hline
\end{tabular}


Table 5 Statistics of Freight Intensive Sector (FIS) commercial establishments

\begin{tabular}{|c|c|c|c|c|c|c|c|c|c|}
\hline CIIU & $\mathrm{N}$ & Statistics & $\begin{array}{l}\text { Employees } \\
\text { (full and part time) }\end{array}$ & $\begin{array}{l}\text { Est. area } \\
\text { (sq.m) }\end{array}$ & $\begin{array}{l}\text { Freight attraction } \\
\text { (Kg/day) }\end{array}$ & $\begin{array}{l}\text { Freight production } \\
\text { (Kg/day) }\end{array}$ & $\begin{array}{l}\text { FTA deliveries } \\
\text { (trips/day) }\end{array}$ & $\begin{array}{l}\text { FTP shipments } \\
\text { (trips/day) }\end{array}$ & Vendors \\
\hline \multirow[t]{3}{*}{ Mining (CIIU 10-14) } & \multirow[t]{3}{*}{39} & Mean & 4.23 & 87.26 & 51.27 & 4.44 & 0.91 & 0.19 & 5.46 \\
\hline & & Std.Dev & 5.28 & 110.29 & 93.90 & 16.00 & 0.96 & 0.55 & 12.62 \\
\hline & & Min-Max & $1-33$ & $10-600$ & $0.1-444.2$ & $0-86.5$ & $0-4.2$ & $0-2.5$ & $1-80$ \\
\hline \multirow{3}{*}{$\begin{array}{l}\text { Light manufacturing } \\
\text { (CIIU 15-19) }\end{array}$} & \multirow[t]{3}{*}{352} & Mean & 6.18 & 130.01 & 116.38 & 24.03 & 0.81 & 0.83 & 4.09 \\
\hline & & Std.Dev & 14.40 & 276.81 & 710.10 & 148.75 & 1.27 & 5.63 & 7.02 \\
\hline & & Min-Max & $0.9-220$ & $1-2800$ & $0.1-11,779.3$ & $0-2538.5$ & $0-13.8$ & $0-100.7$ & $1-70$ \\
\hline \multirow{3}{*}{$\begin{array}{l}\text { Medium manufacturing } \\
\text { (CIIU 20-29) }\end{array}$} & \multirow[t]{3}{*}{408} & Mean & 10.54 & 258.52 & 131.50 & 57.73 & 1.25 & 1.83 & 4.57 \\
\hline & & Std.Dev & 31.32 & 1587.77 & 535.39 & 445.60 & 7.20 & 19.15 & 8.42 \\
\hline & & Min-Max & $1-417$ & $2-30,000$ & $0-9038.5$ & $0-8538.5$ & $0-142.3$ & 0-384.6 & $1-86$ \\
\hline \multirow{3}{*}{$\begin{array}{l}\text { Heavy manufacturing } \\
\text { (CIIU 30-36) }\end{array}$} & \multirow[t]{3}{*}{195} & Mean & 8.02 & 102.98 & 42.85 & 13.99 & 0.67 & 0.25 & 3.11 \\
\hline & & Std.Dev & 19.38 & 156.10 & 176.12 & 92.74 & 1.22 & 0.77 & 4.28 \\
\hline & & Min-Max & $1-150$ & $3-1200$ & $0.1-1765.4$ & $0-1153.8$ & $0-9.2$ & $0-7.7$ & $1-48$ \\
\hline \multirow{3}{*}{$\begin{array}{l}\text { Recycle stores } \\
\text { (CIIU 37) }\end{array}$} & \multirow[t]{3}{*}{22} & Mean & 9.92 & 188.50 & 179.78 & 339.91 & 0.70 & 0.42 & 2.32 \\
\hline & & Std.Dev & 16.78 & 207.27 & 490.27 & 641.22 & 1.09 & 0.50 & 1.84 \\
\hline & & Min-Max & $0.9-77$ & $12-700$ & $0-2269.2$ & $0-2538.5$ & $0-4.6$ & $0-1.9$ & $1-7$ \\
\hline \multirow[t]{3}{*}{ Construction (CIIU 45) } & \multirow[t]{3}{*}{126} & Mean & 10.32 & 144.33 & 57.80 & 23.56 & 1.33 & 1.04 & 3.66 \\
\hline & & Std.Dev & 20.42 & 245.39 & 112.17 & 94.31 & 7.63 & 4.01 & 6.04 \\
\hline & & Min-Max & $1-200$ & $4-1900$ & $0.1-615.4$ & $0-923.1$ & $0-85.6$ & $0-26.9$ & $1-60$ \\
\hline \multirow[t]{3}{*}{ Repair stores (CIIU 50) } & \multirow[t]{3}{*}{194} & Mean & 7.32 & 187.25 & 111.77 & 45.60 & 0.67 & 0.43 & 3.63 \\
\hline & & Std.Dev & 14.94 & 607.59 & 389.97 & 203.04 & 1.00 & 1.54 & 5.68 \\
\hline & & Min-Max & $1-137$ & $2-8000$ & $0-4043.5$ & $0-2000$ & $0-6.2$ & $0-15.4$ & $1-50$ \\
\hline \multirow{3}{*}{$\begin{array}{l}\text { Fuel/lubricants } \\
\text { distribution (CIIU 505) }\end{array}$} & \multirow[t]{3}{*}{12} & Mean & 3.56 & 85.92 & 491.00 & 0.29 & 0.58 & 0.08 & 2.67 \\
\hline & & Std.Dev & 2.51 & 97.87 & 1169.64 & 1.00 & 0.44 & 0.27 & 1.72 \\
\hline & & Min-Max & $1-9$ & $8-300$ & $0.5-4043.5$ & $0-3.5$ & $0.1-1.2$ & $0-0.9$ & $1-6$ \\
\hline \multirow[t]{3}{*}{ Wholesale (CIIU 51) } & \multirow[t]{3}{*}{212} & Mean & 5.90 & 166.86 & 137.37 & 98.39 & 0.69 & 0.72 & 2.87 \\
\hline & & Std.Dev & 8.93 & 434.60 & 511.13 & 674.34 & 1.13 & 3.52 & 2.94 \\
\hline & & Min-Max & $1-80$ & $6-4000$ & $0-4769.2$ & $0-8384.6$ & $0-7.7$ & $0-46.2$ & $1-30$ \\
\hline \multirow[t]{3}{*}{ Retail (CIIU 52) } & \multirow[t]{3}{*}{477} & Mean & 4.73 & 128.08 & 81.44 & 19.13 & 1.78 & 2.64 & 3.87 \\
\hline & & Std.Dev & 10.07 & 690.58 & 501.27 & 135.83 & 21.13 & 42.73 & 8.54 \\
\hline & & Min-Max & $0.9-80$ & $1-4500$ & $0.02-1765.39$ & $0.04-253.85$ & $0.04-9.23$ & $0.04-26.92$ & $1-70$ \\
\hline \multirow{3}{*}{$\begin{array}{l}\text { Accommodation and } \\
\text { food (CIIU 55) }\end{array}$} & \multirow[t]{3}{*}{224} & Mean & 4.64 & 147.93 & 92.65 & 3.59 & 0.95 & 0.26 & 3.58 \\
\hline & & Std.Dev & 6.70 & 437.86 & 927.50 & 37.19 & 0.88 & 1.39 & 3.78 \\
\hline & & Min-Max & $0.9-60$ & $4-6000$ & $0-13,882.3$ & $0-542.3$ & $0-6.2$ & $0-13.5$ & $1-45$ \\
\hline \multirow{3}{*}{$\begin{array}{l}\text { Transport /warehouse } \\
\text { (CIIU 60-64) }\end{array}$} & \multirow[t]{3}{*}{143} & Mean & 39.70 & 211.80 & 44.91 & 38.02 & 0.64 & 0.80 & 2.52 \\
\hline & & Std.Dev & 350.96 & 848.24 & 184.99 & 217.91 & 1.16 & 2.40 & 4.01 \\
\hline & & Min-Max & $1-4200$ & $3-9800$ & $0-1600$ & $0-2384.6$ & $0-7.7$ & 0-19.2 & $1-30$ \\
\hline Machine renting & 49 & Mean & 3.00 & 83.90 & 16.02 & 24.41 & 0.63 & 0.22 & 2.52 \\
\hline & & Std.Dev & 2.45 & 124.59 & 55.09 & 124.11 & 0.84 & 0.63 & 1.93 \\
\hline & & Min-Max & $1-14$ & $8-620$ & $0-307.7$ & $0-692.3$ & $0-3.8$ & $0-3.1$ & $1-10$ \\
\hline
\end{tabular}

Notes: (1) The column labeled $N$ corresponds to the sample size (number of observations);

(2) Shipments excludes zero values; (3) Employment is calculated as full-time employees + 0.45 part-time employees; (4) FIS establishments generate on average $135 \mathrm{~kg} /$ establishment/day

SIS ones, with 135 and 42.7 daily $\mathrm{kg} /$ establishment respectively. Among freight-related establishments, recycling establishments, fuel distribution, wholesale and medium manufacturing have particularly high freight generation with $519.7,491.3,235.8$, and 189.2 daily $\mathrm{kg} /$ establishment, respectively. It is noteworthy that 
Table 6 Statistics of non-freight intensive sector (service-oriented) commercial establishments

\begin{tabular}{|c|c|c|c|c|c|c|c|c|c|}
\hline $\mathrm{CIIU}$ & $\mathrm{N}$ & Statistics & $\begin{array}{l}\text { Employees } \\
\text { (full and part time) }\end{array}$ & $\begin{array}{l}\text { Est. area } \\
\text { (sq.m) }\end{array}$ & $\begin{array}{l}\text { Freight attraction } \\
\text { (Kg/day) }\end{array}$ & $\begin{array}{l}\text { Freight production } \\
(\mathrm{Kg} / \text { day })\end{array}$ & $\begin{array}{l}\text { FTA deliveries } \\
\text { (trips/day) }\end{array}$ & $\begin{array}{l}\text { FTP shipments } \\
\text { (trips/day) }\end{array}$ & Vendors \\
\hline \multirow[t]{3}{*}{ Utilities(CIIU 40-41) } & \multirow[t]{3}{*}{3} & Mean & 4.48 & 53.33 & 2.17 & 0.04 & 0.13 & 0.05 & 2.00 \\
\hline & & Std.Dev & 1.78 & 31.75 & 2.65 & 0.07 & 0.04 & 0.09 & 1.00 \\
\hline & & Min-Max & $3-6.5$ & $35-90$ & $0.2-5.2$ & $0-0.1$ & $0.1-0.2$ & $0-0.2$ & $1-3$ \\
\hline \multirow{3}{*}{$\begin{array}{l}\text { Financial services } \\
\text { (CIIU 65-67) }\end{array}$} & \multirow[t]{3}{*}{67} & Mean & 17.01 & 197.94 & 12.38 & 4.06 & 1.27 & 0.40 & 3.30 \\
\hline & & Std.Dev & 47.64 & 854.02 & 38.14 & 22.87 & 4.66 & 1.02 & 6.22 \\
\hline & & Min-Max & $1-300$ & $8-7000$ & $0-278.3$ & $0-184.6$ & $0-30.8$ & $0-4.6$ & $1-40$ \\
\hline \multirow{3}{*}{$\begin{array}{l}\text { Real state } \\
\text { (CIIU 72-74) }\end{array}$} & \multirow[t]{3}{*}{210} & Mean & 8.84 & 90.32 & 17.32 & 15.23 & 0.58 & 0.29 & 2.58 \\
\hline & & Std.Dev & 32.34 & 206.36 & 51.56 & 100.86 & 1.00 & 0.80 & 3.24 \\
\hline & & Min-Max & $0.9-400$ & $1-2500$ & $0-338.5$ & 0-1000 & $0-6.6$ & $0-7.7$ & $1-30$ \\
\hline \multirow[t]{3}{*}{ Education (CIIU 80) } & \multirow[t]{3}{*}{47} & Mean & 17.13 & 288.45 & 14.85 & 9.83 & 0.49 & 0.89 & 3.23 \\
\hline & & Std.Dev & 56.30 & 309.20 & 29.09 & 67.32 & 1.22 & 6.06 & 8.58 \\
\hline & & Min-Max & $1-390$ & $9-1600$ & $0-126.9$ & $0-461.5$ & $0-6.9$ & $0-41.5$ & $1-60$ \\
\hline \multirow{3}{*}{$\begin{array}{l}\text { Health and social } \\
\text { services (CIIU 85) }\end{array}$} & \multirow[t]{3}{*}{47} & Mean & 17.13 & 288.45 & 14.85 & 9.83 & 0.49 & 0.89 & 3.23 \\
\hline & & Std.Dev & 56.30 & 309.20 & 29.09 & 67.32 & 1.22 & 6.06 & 8.58 \\
\hline & & Min-Max & $1-390$ & $9-1600$ & $0-126.9$ & $0-461.5$ & $0-6.9$ & $0-41.5$ & $1-60$ \\
\hline \multirow{3}{*}{$\begin{array}{l}\text { Other services } \\
\text { (CIIU 90-93) }\end{array}$} & \multirow[t]{3}{*}{54} & Mean & 12.05 & 152.04 & 159.02 & 4.41 & 0.38 & 0.08 & 3.00 \\
\hline & & Std.Dev & 41.67 & 283.59 & 941.86 & 24.28 & 0.47 & 0.33 & 2.79 \\
\hline & & Min-Max & $0.9-300$ & $10-1600$ & $0-6925.7$ & $0-176.9$ & $0-2$ & $0-2.3$ & $1-20$ \\
\hline
\end{tabular}

Notes: (1) The column labeled $N$ corresponds to the sample size (number of observations);

(2) Shipments excludes zero values; (3) Employment is calculated as full-time employees + 0.45 part-time employees; (4) Non-FIS establishments generate on average $42.7 \mathrm{~kg} / \mathrm{establishment/day}$

establishments in mining, heavy manufacturing and transport/warehousing are among the ones with the lower freight generation for freight-intensive sectors with $55.7,56.8,82.9$ daily $\mathrm{kg} / \mathrm{establishment} \mathrm{respectively.} \mathrm{The}$ latter could be a result of the type of activities covered by these sectors in the area of study. Mining covers extraction of stones and oil, and other mining support activities, which are not very common in Medellin. Heavy manufacturing covers motor vehicles, trailers and semitrailers, machinery and equipment, and the like that is not very common in Medellin either, that could explain the low values of freight generation in those sectors in the city. Those values are much higher in other places of the country (e.g., el Cerrejón) and Medellin just receives the cargo (freight attraction) more than sending the cargo (freight production).

For SIS, average freight generation does not exceed 40 daily $\mathrm{kg} / \mathrm{establishments}$ with the exception of other services (163.4 daily $\mathrm{kg} / \mathrm{establishment).} \mathrm{In} \mathrm{essence,} \mathrm{these}$ numbers confirm that freight generation tends to be higher for freight-related establishments than for service-related ones.

In the case of freight trip generation (attraction plus production), FIS establishments generate, on average, more freight trips than service-oriented ones, with 2.3 and 1.0 daily trips/establishment respectively (more than 2 times larger). Furthermore, the data shows that $70 \%$ of establishments only receive shipments while about a $30 \%$ also send shipments to their customers. Among the freight-related sectors, retail, medium manufacturing and construction have the highest freight trip generation with 4.4, 3.1, and 2.4 daily trips/establishment, respectively; while heavy manufacturing, machine renting and fuel/lubricants distribution have the lowest with less than 1 daily trip. For service-related sectors, financial services, education and health and social services have the highest freight trip generation with 1.7, 1.4 and 1.4 daily trips respectively. It is noteworthy that some

Table 7 Statistics of all commercial establishments

\begin{tabular}{|c|c|c|c|c|c|c|c|}
\hline Statistics & $\begin{array}{l}\text { Employees } \\
\text { (full and part time) }\end{array}$ & $\begin{array}{l}\text { Est. area } \\
\text { (sq.m) }\end{array}$ & $\begin{array}{l}\text { Freight attraction } \\
\text { (Kg/day) }\end{array}$ & $\begin{array}{l}\text { Freight production } \\
\text { (Kg/day) }\end{array}$ & $\begin{array}{l}\text { FTA } \\
\text { (trips/day) }\end{array}$ & $\begin{array}{l}\text { FTP } \\
\text { (trips/day) }\end{array}$ & Vendors \\
\hline Mean & 9.14 & 157.37 & 90.58 & 34.26 & 0.99 & 1.05 & 3.58 \\
\hline Std.Dev & 80.45 & 743.24 & 520.32 & 283.49 & 9.12 & 18.79 & 6.39 \\
\hline Min-Max & $0.9-4200$ & $1-30,000$ & $0-13,882.3$ & $0-8538.5$ & $0-461.5$ & 0-923.1 & $1-170$ \\
\hline
\end{tabular}

Notes: (1) Shipments excludes zero values; (2) Employment is calculated as full-time employees + 0.45 part-time employees; (3) Sample size: 2947 establishments 
sectors in the service-related sectors have higher freight trip generation than for freight-related sectors. This could be to the use of small trucks (generating more truck-trips) and not the amount of cargo transported.

This survey inquired about the number of vendors (small suppliers located in the CBD), which is not a common practice for freight surveys. This information can provide valuable insight on the type of activities taking place for each sector and to explain freight trip generation. As shown in the tables, the sampled establishments have 3.6 vendors per establishment on average. Freight-related sectors have on average 3.7 vendors per establishment; while service-related sectors have 2.9 vendors per establishment. The sectors with more vendors are mining (5.5 vendors/establishment), medium manufacturing (4.6 vendors/establishment), light manufacturing (4.1 vendors/establishment) and retail (3.87 vendors/establishment). For service-related sectors, the averages are more homogenous with all of them having between 2 and 3 vendors per establishment.

These descriptive statistics highlight the differences across sectors and depict the different freight and business size patterns. One important observation is that sectors with higher business size are not necessarily the ones generating more freight or freight trips; also, sectors with the highest freight generation are not necessarily the ones with the highest freight trip generation. This can be explained by the different shipment sizes and the types of freight vehicles used in different sectors.

\subsection{Planning implications}

Considering that 1) there is a profound lack of information about the amount of freight, freight trips and service trips in urban areas; and 2) this lack of information prevents that planners and transportation engineers realize about the magnitude of the problem and find adequate solutions to freight issues; this study provides a good start of how can we shed light on decision makers to continue planning the cities, but now considering the movement of goods in a more reliable fashion. Thus, this paper contributes to this gap in the in the quantification of the problem based on a freight study and its findings. As an example of this, and based on the freight data collected in this study and its results, the local government decided to start using the freight information to analyze projects, programs and policies to improve freight transportation system in the Medellin metropolitan area. Although it took almost 5 years after this first study ended, in 2017 the Medellin Department of Transportation and the Area Metropolitana del Valle de Aburra (leader public institution that is the emission/ transportation authority in the area) decided to expand this study in three scopes: 1) Update the freight OD matrix; 2) Characterize the freight movements with complementary studies (e.g., large traffic generators, service trips), and 3) Propose freight policies to improve freight transportation system in the Medellin metropolitan area. The project is currently underway and it is a proof that starting to collect freight data and analyzing it could lead the public sector to increase the interest in freight planning that obviously will help the development of urban areas, where freight is and will be a constant.

\section{Conclusions}

This paper seeks to analyze freight generation and freight trip generation patterns in the metropolitan area of Medellin, Colombia; and to suggest how these freight patterns should be considered for future planning decisions. In doing so, this study presents the basic freight data collection techniques used to depict all the complexity of freight distribution in metropolitan areas. The studies consisted in an external cordon survey to catch the cargo entering and exiting from the area; an establishment survey applied to small and medium size commercial establishment to study the internal movement of cargo; and a series of interviews to some companies of carries and trucks drivers with the objective of precise some logistics practices and to have a more deep knowledge of the urban freight generation. All these surveys complement each other, and must be conducted to have a good depiction of the freight movements in urban areas.

As expected, it was found that in the Medellin Metropolitan Area, freight intensive sector establishments generates, on average, significantly more cargo (freight attraction plus production) than the non-freight intensive sector (service-oriented) ones. Moreover, the authors found that the number of vendors (suppliers) of the commercial establishments can be obtained thru freight surveys (which is not a common practice). This information can provide valuable insight on the type of activities taking place for each sector and to explain freight trip generation.

The analyses of the surveys allow the decision makers to understand the nature of the cargo and the generation patterns in different type of establishments. This characterization of the freight patterns is vital for the forecasting of the behavior of the cargo and it is the main input to perform freight demand modeling for city planning, especially for developing countries, where there are too many budget constraints.

\section{Endnotes}

${ }^{1} \mathrm{~A}$ compendium of these strategies can be found in [1].

${ }^{2}$ For more information about freight studies, please see [4]

${ }^{3}$ The data about trash and debris were obtained from information provided by the Metropolitan Area of the Aburra Valley agency [4] 
${ }^{4}$ For instance, the amount of freight moved per person per day in New York City is about twice $(50 \mathrm{~kg} /$ person/day) than for Medellin Metropolitan Area [6].

${ }^{5}$ It is important to note that the amount of freight moved per person per day ( $25 \mathrm{~kg}$ in Medellin) is different to the amount of freight consumed by a person per day (about 1-2 kg) that could be similar in different countries.

\section{Acknowledgements}

The research is based on the freight surveys that were funded by the Metropolitan Area of Aburra Valley and the Municipality of Medellin. The survey was conducted by the Universidad Nacional de Colombia at Medellin and advised by the VREF Center of Excellence for Sustainable Urban Freight Systems at the Rensselaer Polytechnic Institute.

\section{Authors' contribution}

All authors read and approved the final manuscript.

\section{Competing interests}

The authors declare that they have no competing interests.

\section{Publisher's Note}

Springer Nature remains neutral with regard to jurisdictional claims in published maps and institutional affiliations.

\section{Author details}

'Department of Civil Engineering, Universidad Nacional de Colombia at Medellin, Calle 65 \# 78-28, M1-110 Medellin, Colombia. ${ }^{2}$ Department of Technology Management and Economics, Chalmers University of Technology, Vera Sandbergs Allé 8, Room 3332, SE-412 96 Göteborg, Sweden. ${ }^{3}$ Department of Civil Engineering, Universidad Nacional de Colombia at Medellin, Calle 65 No. 78-28, M1-223 Medellin, Colombia. ${ }^{4}$ Department of Civil and Environmental Engineering, Rensselaer Polytechnic Institute, 110 8th St. JEC 4030, Troy, NY 12180, USA.

Received: 10 January 2017 Accepted: 5 April 2018

Published online: 05 June 2018

\section{References}

1. Holguín-Veras J, Jaller M (2014) Comprehensive freight demand data collection framework for large urban areas. In: González-Feliu J, Semet F, Routhier JL (eds) Sustainable urban logistics: concepts, methods and information systems. Springer-Verlag, Berlin

2. Meyburg A et al (2003) Special report 276: a concept for a national freight data program. Transportation Research Board, Washington, D.C 0309085705, Available: http://www.nap.edu/catalog.php?record_id=10793

3. Allen J, Browne M, Cherrett T (2012) Survey techniques in urban freight transport studies. Transp Rev 32(3):287-311

4. Área Metropolitana del Valle de Aburrá, Municipio de Medellín, and Universidad Nacional de Colombia Sede Medellín (2012) Encuesta Origen Destino de Hogares y de Carga para el Valle de Aburrá. Área Metropolitana del Valle de Aburrá, Medellín Available: http://www.metropol.gov.co/ Movilidad/Documents/Encuesta\%20origen\%20y\%20destino\%20de\%20 hogares\%202012.pdf

5. Holguín-Veras J, Ban J, Jaller M, Destro L, Marquis R (2010) Feasibility study for freight data collection - final report. Rensselaer Polytechnic Institute, Albany Available: http://www.utrc2.org/sites/default/files/pubs/FeasibilityStudy-Freight-Data-Collection-Final.pdf

6. Holguín-Veras J, Sánchez I, González-Calderón C, Sarmiento I, Thorson E (2011) Time-dependent effects on parameters of freight demand models. Transp Res Rec 2224(1):42-50

7. González-Calderón CA, Sánchez-Díaz I, Holguín-Veras J (2011) An empirical investigation on the impacts of spatial and temporal aggregation of empty trips models. In: 4th National Urban Freight Conference. METRANS, Long Beach, $\mathrm{p} 17$

8. Holquín-Veras J, Thorson E (2003) Modeling commercial vehicle empty trips with a first order trip chain model. Transp Res B 37(2):129-148
9. Holguín-Veras J, Thorson E (2003) Practical implications of modeling commercial vehicle empty trips. Transp Res Rec 1833:87-94

10. Holguín-Veras J (2013) Freight demand modeling: state of the art and practice, Presented at the adapting freight models and traditional freight data programs for performance measurement Workshop, Washington, D.C. Available: http://onlinepubs.trb.org/onlinepubs/conferences/2013/Freight/ Holguin-Veras.pdf. Accessed 10 Nov 2016

\section{Submit your manuscript to a SpringerOpen ${ }^{\circ}$ journal and benefit from:}

- Convenient online submission

Rigorous peer review

- Open access: articles freely available online

- High visibility within the field

- Retaining the copyright to your article

Submit your next manuscript at $\boldsymbol{\nabla}$ springeropen.com 